\title{
Perceptions of Spiritual Dryness in Iran During the COVID-19 Pandemic
}

\section{Arndt Büssing ${ }^{1,2,3}$ D Sara Hamideh $\mathrm{Kerdar}^{3} \cdot$ Mohammad Esmaeil Akbari $^{4}$. Maryam Rassouli ${ }^{4}$}

Accepted: 19 July 2021 / Published online: 29 July 2021

(c) The Author(s) 2021

\section{Abstract}

This study addresses perceptions of spiritual dryness (a specific form of spiritual struggle) during the COVID-19 pandemic among Iranian Muslims $(n=362)$, and how these perceptions can be predicted. Spiritual dryness was perceived often to regularly by $27 \%$ and occasionally by $35 \%$. Regression models revealed that the best predictors of spiritual dryness (SDS-7) were usage of mood-enhancing medications, loneliness/social isolation and praying as positive predictors, and being restricted in daily life concerns as negative predictor. The pandemic challenges mental stability of people worldwide and may also challenge trust in God. Reliable and humble support of people experiencing these phases is required.

Keywords Spiritual dryness $\cdot$ Spiritual crisis $\cdot$ Spirituality $\cdot$ Validatio $\cdot$ Spiritual dryness scale $\cdot$ Muslims $\cdot$ Iran $\cdot$ COVID-19 pandemic

\section{Introduction}

Studies have shown that people's attention to spirituality may increase in times of crisis (Rahnama et al., 2012). One of the most important examples of such crises in the twenty-first century is the COVID-19 pandemic, which has affected societies in different ways. From the beginning of this pandemic, the moments of fear, pain, loneliness and the sense of imminent death have been experienced by

Arndt Büssing

Arndt.Buessing@uni-wh.de

1 Faculty of Health, Witten/Herdecke University, Gerhard-Kienle-Weg 4, 59313 Herdecke, Germany

2 Philosophical-Theological Academy, IUNCTUS - Competence Center for Christian Spirituality, Münster, Germany

3 Faculty of Health, Witten/Herdecke University, Herdecke, Germany

4 Cancer Research Center, Shahid Beheshti University of Medical Sciences, Tehran, Iran 
patients and all those who are at risk, as well as anyone who perceives its dangers and adverse outcomes (Büntzel et al., 2020; Büssing et al., 2020a, 2020b; Heidari et al., 2020).

Depending on the influence of spirituality and religion on each society, spirituality is considered as a resource to cope with the adverse impact of diseases on people's health (Weber \& Pargament, 2014). In addition, religions provide a frame of reference for understanding the experience of suffering, pain and finality (Daaleman \& VandeCreek, 2000). Although both terms are often used interchangeably, these are conceptually not identical. In relatively secular societies, spirituality is regarded as a more comprehensive and "individual" opposite of institutional religiosity with its specific doctrines, belief systems and rituals (Büssing, 2012, 2019). Religion is understood as "an institutional and culturally determined approach which organizes the collective experiences of people (faith) into a closed system of beliefs and practices ('form')" (Büssing, 2012), while the more open term spirituality "refers to the individual experiences of the Sacred" or to an individual search for meaning in life along with subsequent values, ethics, rituals and practices (Büssing, 2012, 2019). The broader and more general concept, spirituality, is defined based on religion and culture, affecting people's perception of health and illness (Rahnama et al., 2012). A qualitative study conducted in Iran proposes, "Spirituality is the sublime aspect of human existence bestowed on all humans in order for them to traverse the path of transcendence that is closeness to God (Allah)." (Memaryan et al., 2016). The definition is similar to the previous definitions of this concept, both in its main part (transcendence) and in incorporating a God-centered view of spirituality within the context of an Islamic society (Alzahrani et al., 2016).

In this regard, one may differentiate positive and negative religious coping strategies, with different outcomes on mental health indicators (Weber \& Pargament, 2014). Times of crisis may challenge one's religious convictions and faith while facing negative experiences; one's faith may also be utilized as a resource to cope, when positive experiences take place (Weber \& Pargament, 2014). This may also result in spiritual consolidation or "awakening" and coherence, which is a sense of harmony, connection and meaningfulness (Lips-Wiersma, 2002; Nemati et al., 2017).

Apart from these rather positive aspects, there might be also times of religious affliction ("spiritual struggles") which are associated with a sense of disharmony, disconnection, loss of meaning and purpose in life (Smucker, 1996) as well as leading to passive reactions such as despair, hopelessness, depression and ultimately indifference (Weber \& Pargament, 2014). In fact, religious people may perceive spiritual struggles that either refer to the faith community, to religious doctrines and beliefs, or to God; these struggles may affect their wellbeing (Exline \& Rose, 2013; Exline et al., 2014, 2015; Stauner et al., 2016).

Spiritual struggles are in general an important and diverse field of research, as there are associations between childhood trauma and spiritual struggles in adulthood, Czech participants particularly face demonic struggles (Janů et al., 2020), while alcohol problems were somewhat associated with all types of spiritual struggles, too (Stauner et al., 2019). However, "only moral struggle predicted alcohol problems moderately and independently of religiousness, distress, gender, and non/ 
white ethnicity," as stated by Stauner et al., 2019. Moral injuries were in fact relevant triggers of these general spiritual struggles (Currier et al., 2019), which are associated with suicidal behaviors, too (Currier et al., 2018).

However, not all of these struggles are the indicators of psychopathologic disorder and do not necessarily require a psychological/psychiatric intervention. Some of these spiritual struggles refer to extrinsic factors (i.e., the religious community and their ethics and beliefs), to intrinsic causes (i.e., loss of meaning in life), and some to the relation with God, who is perceived as distant and non-responding (Exline et al. 2013; Büssing et al., 2013, 2020b, 2021c). Therefore, the outcomes might be different, too.

Global crises such as the COVID-19 pandemic may thus challenge a person's religious trust and faith in God who might be regarded as less interested in man's concerns in difficulties in life (Büssing et al., 2021a). In a recent study, Iranian nurses stressed the importance of providing spiritual care in the pandemic period and stated that the lack of this type of care causes spiritual distress in patients. According to the nurses, spiritual care can help to stabilize patients' emotional situation during the COVID-19 pandemic and may allow them to "continue living" (Rezaee et al., 2020).

It is assumed that one way to cope with the social and individual overcome of the COVID-19 pandemic is strengthening religious faith, because developing a stronger bond with God would reduce or eliminate distress, anxiety and stress and increase hope and peace (Kowalczyk et al., 2020; Roman et al., 2020). This applies the ability to utilize persons' faith in terms of positive religious coping. Religions, in general, and religious communities, specifically, may further contribute to promote health politics, social and health behaviors, meaning finding and coping strategies (Barmania \& Reiss, 2020). However, depending on the cultural and religious background, people may or may not utilize their faith to cope with the COVID-19 pandemic. For example, in German patients with cancer, interest in spirituality during the pandemic was rather low, while their perception of nature as a source of consolidation, and quiet times of reflection were of stronger interest (Büssing et al., 2020d). That faith is a strong hold to them was stated by only $31 \%$. Moreover, during the course of the pandemic, tumor patients' religious trust and prayer practices were significantly higher directly after the first lockdown compared to the beginning of the second wave of the pandemic (Büssing et al., 2021a). This could mean that the stress related to the pandemic and its burden may have an impact on their spiritual attitudes and practices.

Iran is one of those countries with relatively high death rate due to the COVID-19 infections (Rassouli et al, 2020). Here, 98\% of people are Muslims (Rassouli \& Sajjadi, 2016), and their religious belief is considered as an important source for coping with stressors. In fact, spirituality is an essential element in Iranians' lives and is rooted in their culture and history (Nemati et al., 2017). However, some Iranians, based on their spiritual beliefs, may nevertheless have contradictory opinions on life events and God (Nemati et al., 2017). Some may consider God responsible for the negative life events and regard themselves as victims (Exline et al., 2014), interpreting these events as punishment and injustice from God. Moreover, in Western societies, negative life events (i.e., illness) are interpreted as not only the interruption of life, failure or punishment, but also as a challenge or as a valuable motive for growth 
(Büssing \& Fischer, 2009; Büssing \& Surzykiewicz, 2015; Degner et al., 2003). With respect to Islam, it should be noted that justice is one of the principles and disbelief is considered as heresy. Yet, this might be a misconception of "divine justice," considering justice as laws that God is obliged to follow (Rokni, 2008). However, according to Islam, God is the source of justice and everything He does is justice; therefore, He has set a proper path for every creature to reach perfection (Motahhari, 2013). In this regard, studies have shown that spirituality, through creating a positive attitude, may foster outcomes such as a sense of worthiness and peace, acceptance of current situation and patience (Soleimani et al., 2016). Thus, in such situations, very religious people may regard these apparently devastating crises as the best blessings in life (Nemati et al., 2017), while others struggle with their faith because they cannot share this perspective.

The times of crisis are also the times of religious struggles and insecurities (Exline et al., 2014). In fact, spiritual struggles, doubts about God and His closeness, as well as the perceived distance toward God, who seems not to care about mans' concerns, are everlasting experiences and have been articulated for millennia (Büssing \& Dienberg, 2019). This may also be true during the COVID-19 pandemic. Therefore, identifying the barriers such as spiritual dryness and its predictors is of great importance.

Spiritual dryness refers to the perception that God is distant, regardless of our efforts to get close to Him, that one's prayers go unanswered, as well as the feeling of being completely abandoned by God, the feelings of being "spiritually empty" and not being able to give any more (Büssing et al., 2013, 2020b, 2021c). Similar concepts described in the mystic literature are "dark night of the soul," "spiritual desolation" or "desert experience," which nevertheless may be different from a theoretical point of view (Büssing et al., 2020a). These concepts refer primarily to spiritual struggles without the assumption of an underlying psychopathology. Nevertheless, in palliative medicine, there is an important topic, which may be in part related to spiritual dryness, termed "spiritual distress" (Puchalski et al., 2018). It refers to any impairment in the experience of meaningful life that should normally be acquired through communication with self, others, the world or a superior power (Caldeira et al., 2017). Spiritual distress refers to both, depressive symptoms (i.e., depression, anxiety, hopelessness, disturbance of sleep) and spiritual distress (i.e., feeling of being abandoned by God, religious doubt, loss of faith). Spiritual distress is thus a broad concept and does not necessarily depend on a particular religion or specific beliefs. Both religious and non-religious individuals may experience such spiritual distress (Nolan et al., 2020). However, "spiritual distress" is usually seen as disease related or triggered by the impact of disease and its prognosis, while spiritual dryness is also and foremost experienced by "healthy" persons (Büssing et al., 2020a).

The underlying causes of spiritual dryness can be differentiated as extrinsic and intrinsic (not in terms of exclusive states, but polarities) (Büssing et al., 2020b). Some attributed these perceptions to temptations of evil spirits or hint that spiritual life needs to be changed, or to the need to let go of all materialistic concerns, or to an "inertia of the heart" in terms of a boredom or negligence (Büssing et al., 2020a). Modern scholars discuss that spiritual dryness can also be seen in the context of 
depressive states (Bäumer \& Plattig, 2008; Durà-Vilà, 2017; May, 2009; Ott, 1982). In several studies on Christian pastoral workers, religious brothers and sisters, and lay people, spiritual dryness was experienced by 12 to $14 \%$ often to regularly (Büssing \& Dienberg, 2019; Büssing et al., 2016, 2017a, 2017b, 2018a, 2018b, 2018c) and by $16 \%$ in Seventh-day Adventists (Büssing et al., 2021c). The underlying causes were heterogeneous, ranging from the lack of ability to perceive the Sacred in life and low coherence in life to emotional exhaustion and depressive symptoms (Büssing et al., 2016, 2017a, 2017b). Excessive Spiritual demands, the low perception of the Sacred in daily life concerns, difficulties in prayer life as well as higher influence of emotional exhaustion and low wellbeing were reported, too (Büssing et al., 2021c). Depending on the cohort, the predictors of spiritual dryness perceptions may vary. The experience of spiritual dryness is not necessarily a matter of "spiritual weakness," but is an existential experience that requires support, as it may be a turning point toward either spiritual development and the consolidation of faith, or spiritual desolation and loss of faith (or disinterest) (Büssing \& Dienberg, 2019; Martini \& Bader, 2005).

This study aims to find out whether and how the Muslims in Iran would perceive the phases of spiritual dryness, and how these are related to the indicators of spirituality and wellbeing as reported in other studies (Büssing et al., 2016, 2017a, 2017b, 2018a, 2018b, 2018c, 2021c). The perception of awe/gratitude (as a perceptive aspect of spirituality) and religious practices (particularly the spontaneous private prayers rather than the frequency of obligatory religious practices and prayers) were both negatively related to spiritual dryness in German pastoral workers (Büssing et al., 2017b); thus, similar associations can be assumed among Iranian Muslims, too. Furthermore, it is suspected that low wellbeing, low life satisfaction and a variety of stressors related to the COVID-19 pandemic (e.g., daily life restrictions, the feelings of being stressed/under pressure, of being fearful/insecure, lonely/socially isolated, as well as the financial burden) will have an impact on the perception of spiritual dryness. The impact of health behaviors on spiritual dryness has never been investigated and is part of this analysis.

\section{Materials and Methods}

\section{Study Participants}

The participants from Iran took part in an anonymous online survey with standardized measures through convenience sampling method from December 2020 to February 2021. The study was approved by the Ethic Committee of Cancer Research Center, Shahid Beheshti University of Medical Sciences (IR.SBMU.CRC. Rec.1399.027). The invitations to participate, along with a short explanation about the study and its purpose, were posted in several social media platforms as well as different groups on WhatsApp and Telegram and forwarded in various Iranian networks with the request to forward it with the purpose of snowball sampling. Upon willingness to participate in the study, the participants signed an online consent form before accessing the questionnaire. Neither the concrete identifying personal details 
nor the IP addresses were recorded to guarantee anonymity. The inclusion criteria were being a Farsi speaker and over 18 years of age. The sample also included seven Muslims with Iranian nationality living in other countries.

\section{Measures}

The online questionnaire consisted of basic sociodemographic questions regarding gender, age, nationality and religious affiliation. All the measures which were used in the Farsi version, will be described below. The translation process started with the first translation from German/English language to Farsi by a bilingual researcher. Afterward, it was checked and adjusted by an additional bilingual researcher. After back translation into English, the inconsistencies were addressed. After the Farsi version was prepared, the tool was psychometrically evaluated by measuring the content validity and performing cognitive assessment. In order to evaluate the content validity, seven experts in nursing, psychology and psychometrics were asked to express their opinions on the compatibility of the items with the cultural circumstances of Iran. Then the cognitive assessment of the tool was performed using the opinions of 10 participants meeting the inclusion criteria (individuals over 18, fluent in Farsi) in order to determine the simplicity and the comprehensibility of the items.

\section{Spiritual Dryness}

The perception of "spiritual dryness" was assessed with the Spiritual Dryness Scale (SDS). It primarily uses six items with good internal consistency (Cronbach's $\alpha=0.87$ ) (Büssing et al., 2013). Specific statements refer to the feelings that God is distant, that one's prayers go unanswered, as well as the feeling of being "spiritually empty" or not able to give any more (in terms of spiritual exhaustion) and being abandoned by God. The items of this instrument were formulated in order to fit into the daily life experiences of religious individuals. For this analysis, we added an additional item, which asks for a "deep longing for God" (item SDS0). The response options on a Likert scale were not at all (1), rarely (2), occasionally (3), fairly often (4) and regularly (5). The SDS scores are the mean scores and represent the perceived lack/shortage.

The instrument uses three further items to address whether one has "found ways to deal with these feelings" in terms of coping strategies, and behaviors and perceptions when these phases would overcome: "These feelings inspire me to help others more." and "After these phases, I experience greater spiritual serenity and depth." The scoring is the same as the above mentioned.

\section{Awe and Gratitiude}

Awe/Gratitude as an indicator of experiential spirituality was measured with the 7-item Gratitude/Awe questionnaire (GrAw-7) (Büssing et al., 2018c) which has good psychometric properties (Cronbach's $\alpha=0.82$ ). This measure has a clear focus on the experiential aspects of being moved and touched by certain moments and 
or distinct locations, nature-related reactions of pausing daily activities and the subsequent feelings of awe and gratitude. The specific items are, "I stop and then think of so many things for which I'm really grateful," "I stop and am captivated by the beauty of nature," "I pause and stay spellbound at the moment" and "In certain places, I become very quiet and devout." All the items were scored on a 4-point scale: 0 , never; 1 , seldom; 2 , often; and 3, regularly, based on a $100 \%$ scale. The resulting mean values thus range from 0 to 100 .

\section{Faith as a Strong Hold}

To measure a more specific form of religiosity, we added item A37 from the Reliance on God's Help scale (Büssing et al., 2015), which asks whether faith is a strong hold in difficult times. Agreement or disagreement was scored on a 3-point scale: 0, disagreement; 2, indifference; and 3, agreement. This item was used as a differentiating variable to assess intrinsic religiosity in terms of attitude.

\section{Praying and Meditation}

To assess the behavioral and ritual aspects of religiosity, the frequency of praying and meditation was differentiated, ranging from never (0), at least once per month (1), at least once per week (2), to at least once per day (3). Praying was further differentiated as an obligation, i.e., performing the obligatory prayers (Salat), or as a spontaneous reaction, i.e., private prayer (Du'a). The frequency of both was scored as never (0), seldom (1), often (2) and regularly (3).

\section{Wellbeing}

Wellbeing was assessed with the 5-item WHO-Five Well-being Index (WHO-5) (Bech et al., 2003). The representative items are "I have felt cheerful and in good spirits" or "My daily life has been filled with things that interest me." The intensity of feelings refers to the last two weeks and was scored with a 6-step grading scale ranging from at no time (0) to all the time (5). Here, the reported WHO-5 sum scores refer to a $100 \%$ level [0-100], in which the scores $<50$ are the indicators of reduced wellbeing (Toppet al., 2015).

\section{Life Satisfaction}

Life satisfaction was measured using the Brief Multidimensional Life Satisfaction Scale (BMLSS) (Büssing et al., 2009). The items of the BMLSS address intrinsic (oneself, life in general), social (friendships, family life), external (work situation, the place of residence) and prospective dimensions (financial situation, future prospects) of life satisfaction as a multifaceted construct. The internal consistency of the instrument was found to be good in the validation study (Cronbach's $\alpha=0.87$ ). 
In this study, the 10-item version was employed that included satisfaction with the health situation and abilities to deal with daily life concerns (BMLSS-10).

\section{Perception of Burden}

The perceived restrictions of daily life (pressure/stress, anxiety/insecurity, loneliness/social isolation and the restrictions of financial-economic situation related to the COVID-19 pandemic) were measured with five numeric rating scales (NRS), ranging from 0 (not at all) to 100 (very strong) as described (Büssing et al., 2020c). These five variables can be combined in a factor termed "Stressors" (5NRS) with good internal consistency in this sample (Cronbach's $\alpha=0.80$ ).

\section{Frequency of Health Behaviors}

Health behaviors such as physical/sport activities, walking outside in the nature, and taking mood-enhancing medications (in terms of antidepressants or anti-anxiety medications, but not in terms of illicit drugs) were measured with a 4-grade scale (never, at least once per month, at least once per week, at least once per day) as described (Büssing et al., 2020c).

\section{Statistical Analysis}

Descriptive statistics, the analyses of variance (ANOVA), first-order correlations (Spearman rho), regression analyses as well as internal consistency (Cronbach's coefficient $\alpha$ ) and factor analyses (principal component analysis using Varimax rotation with Kaiser's normalization) were computed with SPSS 23.0.

To analyze the predictors of spiritual dryness, we performed three regression models to assess which independent variables would predict SDS scores as a dependent variable: (1) the indicators of spirituality, (2) the indicators of the quality of life and (3) health behaviors such as the intake of mood-enhancing medications.

Given the exploratory character of this study, the significance level of ANOVA and correlation analyses were set at $p<0.01$. With respect to classifying the strength of the observed correlations, we regarded $r>0.5$ as a strong correlation, an $r$ between 0.3 and 0.5 as a moderate correlation, an $r$ between 0.2 and 0.3 as a weak correlation and $r<0.2$ as negligible or no correlation.

\section{Results}

\section{Description of the Sample}

The sample consists of 362 participants from Iran (53\% men; $45 \%$ women; and 2\% "other") with a mean age of $39.5 \pm 17.3$. All were Muslims, most were living in a family household (Table 1). Deep longing for God/Allah was perceived often to 
Table 1 Description of 362 Muslim participants from Iran

\begin{tabular}{|c|c|c|c|}
\hline & $n$ & $\%$ & Mean \pm SD \\
\hline \multicolumn{4}{|l|}{ Sociodemographic data } \\
\hline Gender & 362 & & \\
\hline Male & 193 & 53 & \\
\hline Female & 162 & 45 & \\
\hline Other & 7 & 2 & \\
\hline Age (years) & 302 & & $39.5 \pm 17.3$ \\
\hline Living situation & 362 & & \\
\hline Family household & 290 & 80 & \\
\hline Single & 59 & 16 & \\
\hline other & 13 & 4 & \\
\hline Area of work & 362 & & \\
\hline Administration/management & 24 & 7 & \\
\hline Economy & 39 & 11 & \\
\hline Medicine & 90 & 25 & \\
\hline Psychology & 39 & 11 & \\
\hline Education & 43 & 12 & \\
\hline Craft/trade & 26 & 7 & \\
\hline Other & 101 & 27 & \\
\hline \multicolumn{4}{|l|}{ Indicators of spirituality } \\
\hline Deep longing for God [0-4] & 351 & & $2.62 \pm 1.13$ \\
\hline Not at all/seldom & 58 & 17 & \\
\hline Sometimes & 93 & 27 & \\
\hline Often/regularly & 200 & 57 & \\
\hline Frequency of prayer [0-3] & 330 & & $2.0 \pm 0.9$ \\
\hline Frequency of private prayers (Du'a) [0-3] & 332 & & $1.8 \pm 0.8$ \\
\hline Never & 19 & 6 & \\
\hline Seldom & 95 & 29 & \\
\hline Often & 151 & 46 & \\
\hline regularly & 67 & 20 & \\
\hline Frequency of obligatory prayers (Salat) [0-3] & 333 & & $1.7 \pm 1.1$ \\
\hline Never & 65 & 20 & \\
\hline Seldom & 72 & 22 & \\
\hline Often & 98 & 29 & \\
\hline Regularly & 98 & 29 & \\
\hline \multicolumn{4}{|l|}{ Indicators of wellbeing } \\
\hline Life satisfaction [0-100] & 362 & & $56.3 \pm 16.6$ \\
\hline Wellbeing [0-100] & 362 & & $55.2 \pm 16.0$ \\
\hline Awe/Gratitude [0-100] & 360 & & $57.4 \pm 15.1$ \\
\hline \multicolumn{4}{|l|}{ Perceived burden due to the pandemic } \\
\hline Restrictions of daily life [0-100] & 362 & & $40.2 \pm 27.8$ \\
\hline Pressure/feeling stressed [0-100] & 362 & & $40.7 \pm 28.2$ \\
\hline Anxiety/insecurity [0-100] & 361 & & $38.9 \pm 28.0$ \\
\hline
\end{tabular}


Table 1 (continued)

\begin{tabular}{|c|c|c|c|}
\hline & $n$ & $\%$ & Mean \pm SD \\
\hline Loneliness/social isolation [0-100] & 360 & & $37.8 \pm 29.0$ \\
\hline Financial-economic situation [0-100] & 362 & & $36.1 \pm 28.8$ \\
\hline Perceived Burden (5NRS) [0-100] & 362 & & $38.7 \pm 20.9$ \\
\hline \multicolumn{4}{|l|}{ Health behaviors } \\
\hline Mood-enhancing medications [0-3] & 335 & & $1.3 \pm 1.1$ \\
\hline Sporting activities [0-3] & 334 & & $1.7 \pm 0.9$ \\
\hline Go out for walking [0-3] & 329 & & $1.7 \pm 0.9$ \\
\hline Meditation [0-3] & 331 & & $1.4 \pm 1.1$ \\
\hline
\end{tabular}

Not all participants responded to all items

regularly by $57 \%$, sometimes by $27 \%$ and not at all or seldom only by $17 \%$. Private prayers were practiced more often ( $6 \%$, never) than obligatory prayers $(20 \%$, never). Within the sample, life satisfaction (BMLSS-10) scores were in the upper mid-range and wellbeing scores (WHO-5) in the mid-range, while the perceived burden scores (5NRS) are in the lower mid-range. In addition, the perceptions of Awe/Gratitude were in the mid-range. With respect to the participants' health behavior (Table 1), usage of mood-enhancing medications was quite common, $20 \%$ at a daily level; $25 \%$ at least once per week; $21 \%$ at least once per month; and only $34 \%$ never. Sporting activities were practiced by $62 \%$ at least once per week or at a daily level, and walking outside by $57 \%$ at least once per week or at a daily level. Similarly, meditation (the style and the content were not specified in the questionnaire) was practiced at least once per week or at a daily level by $50 \%$ and praying by $71 \%$ (Table 1).

\section{Perception of Spiritual Dryness}

Among 362 participants, six did not respond to the Spiritual Dryness Scale $(1.7 \%$ non-responder). Here, the indicators of spiritual dryness were perceived with varying intensities by the participants (Table 2). The general experience of spiritual dryness was perceived often to regularly by $27 \%$, occasionally by $35 \%$, rarely by $23 \%$ and not at all by $15 \%$. That prayers go unanswered was experienced often to regularly by $28 \%$, distance from God often to regularly by $16 \%$, while the feeling of being abandoned by God was experienced often to regularly by $24 \%$. Being "spiritually empty" was experienced often to regularly by $28 \%$ and the perception of not being able to emotionally "give" any more by $22 \%$.

Additionally, $42 \%$ of the participants stated that they had often to regularly found ways to cope with these phases; $30 \%$ occasionally; and $28 \%$ seldom or almost never (Table 2). When these phases were overcome, $47 \%$ stated that these feelings of spiritual dryness had often to regularly inspired them to help others more, while $37 \%$ had often to regularly experienced greater spiritual serenity and depth.

Principal component analysis (Varimax rotation) confirms that the 6-item Spiritual Dryness Scale (SDS) can be combined to a single-factor structure in Muslim 


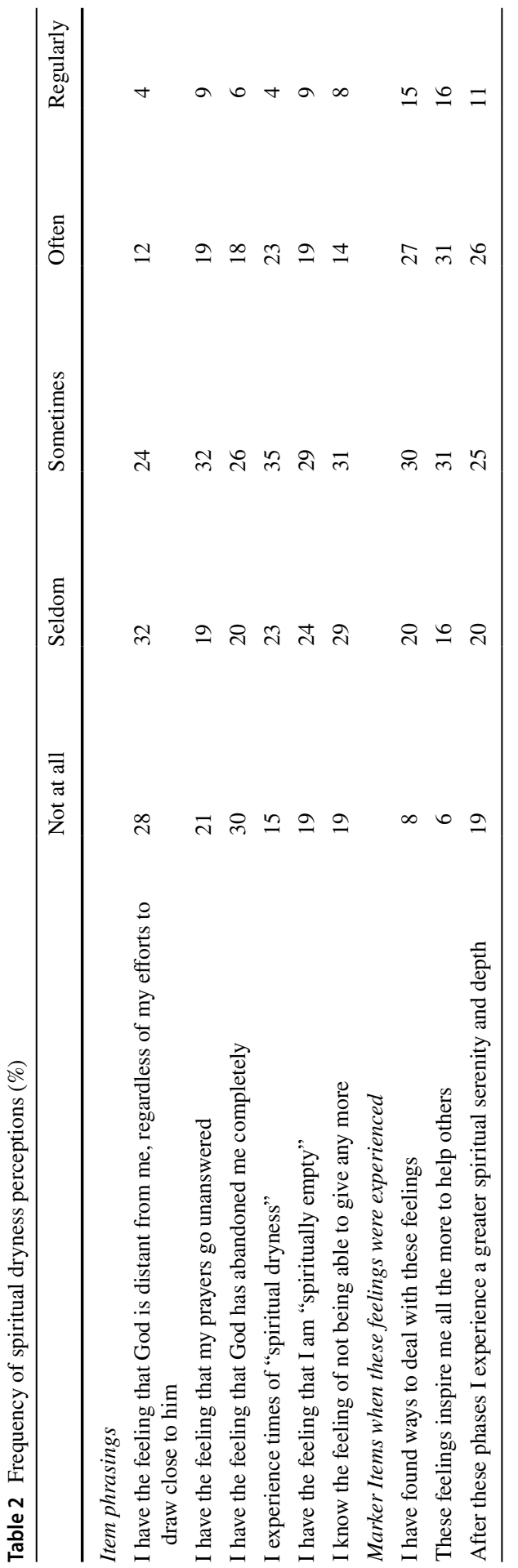




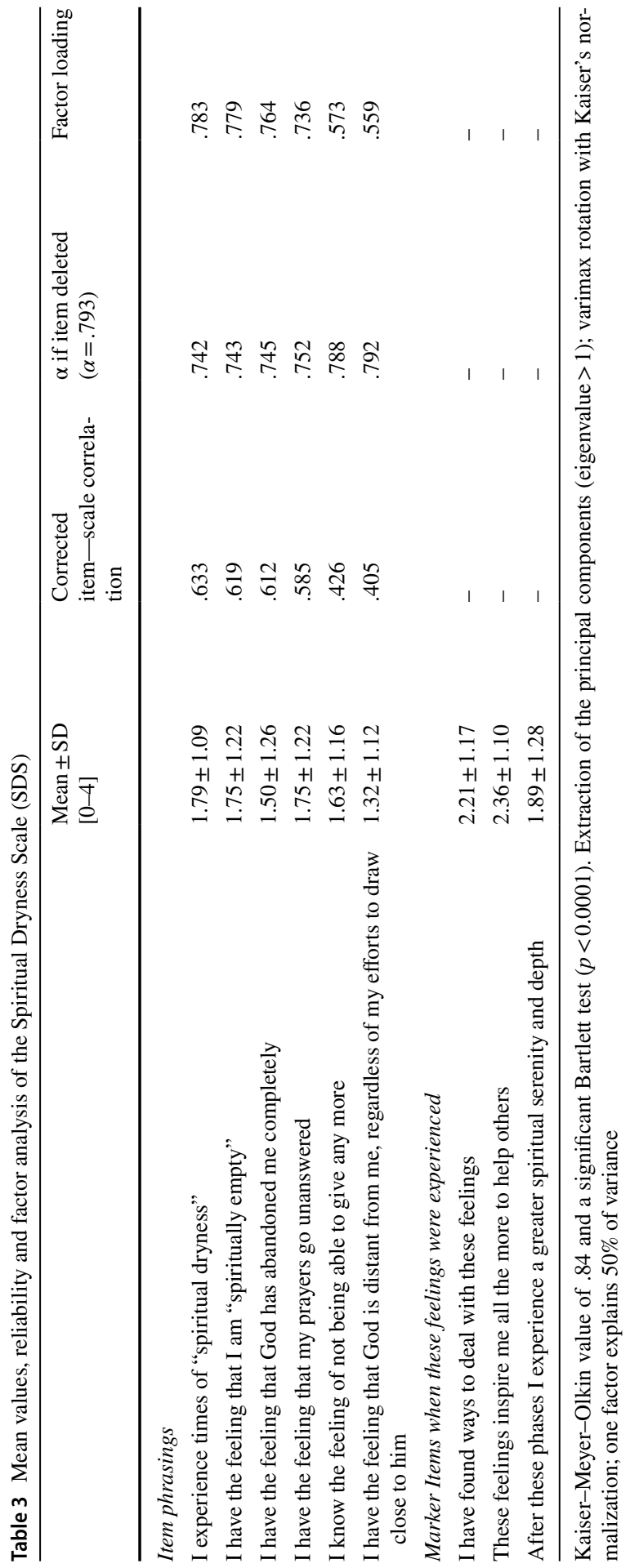


Table 4 SDS scores differentiated for gender and faith as a strong hold (ANOVA)

\begin{tabular}{lccc}
\hline & $N$ & \multicolumn{2}{l}{$\begin{array}{l}\text { Spiritual Dryness } \\
\text { Scale }\end{array}$} \\
\cline { 2 - 4 } & & Mean & SD \\
\hline All participants & 356 & 1.62 & .83 \\
Gender & & & .78 \\
Men & 188 & 1.77 & .84 \\
Women & 161 & 1.43 & .84 \\
Other & 7 & 2.26 & \\
$F$ value & & 10.1 & \\
$p$ value & & $<0.0001$ & .63 \\
Cohen's $d$ (men-women) & & .42 & .68 \\
Faith as strong hold & & & \\
Does not apply & 49 & 1.92 & \\
Neither yes nor no & 158 & 1.75 & \\
Applies a lot & 149 & 1.49 & \\
$F$ value & & 10.7 & \\
$p$ value & & & \\
Cohen's $d$ (no-yes) & & 0.0001 & \\
\hline
\end{tabular}

cohorts too, which explains $50 \%$ of variance and has a good internal consistency (Cronbach's $\alpha=0.79$ ) (Table 3).

The SDS scores were the lowest in women and the highest in the very small subgroup of the people who stated their gender as "other" (Table 4). The differences are still significant $(F=15.8, p<0.0001)$ without "other" gender participants, although the effect size was small (Cohen's $d=0.42$ ). Moreover, people who stated to have faith as a strong hold had lower SDS scores than people who cannot rely on this source (Table 4). Here, the effect size was small (Cohen's $d=0.48$ ). Age was marginally only related to SDS ( $r=0.14, p=0.014$, Spearman rho).

\section{Correlations Between Spiritual Dryness, Indicators of Spirituality, Wellbeing and Health Behaviors}

Spiritual dryness is moderately negatively related to participants' longing for God (Table 5). With respect to praying, it is weakly related to the frequency of private praying, but not significantly related to the frequency of obligatory prayers. Furthermore, awe/gratitude is not significantly related. However, SDS scores are moderately related to lower life satisfaction and only marginally with low wellbeing. Among the COVID-19 pandemic-related stressors, the perception of daily life restrictions was weakly negatively related, while loneliness/social isolation and financial border are weakly positively related to the SDS scores. Being under pressure/stress or feelings of fear and insecurity are not significantly related. The pandemic-related 
Table 5 Correlations between spiritual dryness and indicators of spirituality, wellbeing and health behaviors

\begin{tabular}{lc}
\hline & SDS score \\
\hline Indicators of spirituality & \\
Frequency of praying & $-.279^{* *}$ \\
Frequency private praying (Du'a) & $-.214^{* *}$ \\
Frequency obligatory prayers (Salat) & .053 \\
Awe/gratitude (GrAw-7) & -.065 \\
Indicators of wellbeing & \\
Life satisfaction (BMLSS-10) & $-.396^{* *}$ \\
Wellbeing (WHO-5) & $-.180^{*}$ \\
Perceived burden (5NRS) & .089 \\
Daily life restrictions & $-.266^{* *}$ \\
Under pressure/stressed & .007 \\
Fearful/insecure & .107 \\
Loneliness/social isolation & $.253^{* *}$ \\
Financial burden & $.203^{* *}$ \\
Health behaviors & \\
Mood-enhancing medications & $.453^{* *}$ \\
Sporting activities & .122 \\
Go out for walking & $.168^{*}$ \\
Meditation &. $.350^{* *}$ \\
\hline$* * p<0.001 ; * p<0.01$ (Spearman rho); moderate correlations are \\
highlighted (bold)
\end{tabular}

summarized stressor score (5NRS) is not significantly related to spiritual dryness (Table 5). With respect to health behaviors, the usage of mood-enhancing medications and meditation was moderately positively related to SDS scores, while sporting activities and going out for walking were only marginally related.

\section{Predictors of Spiritual Dryness}

Since several variables significantly related to spiritual dryness perceptions have been found, three regression analyses were performed to assess which independent variables would predict SDS scores as a dependent variable (Table 6). Gender (male or female) was tested first, but was less relevant, thus not used in the following three regression models (data not shown).

In regression model 1 , the indicators of spirituality were tested. These would predict $26 \%$ of SDS score variance, with the frequency of meditation as the best positive predictor, while praying, longing for God and faith as strong holds, are the negative predictors. In regression model 2 , the quality of life indicators were added. Now, the predictors were the frequency of praying (which is a positive predictor now) and being restricted in daily life concerns (as a negative predictor), low life satisfaction and loneliness are further relevant predictors, while wellbeing and burdening financial situation had no significant relevance in this regression model. These 
Table 6 Predictors of spiritual dryness analyzed in three steps

\begin{tabular}{|c|c|c|c|c|c|c|c|c|c|}
\hline & \multicolumn{3}{|c|}{ Model 1: $R^{2}=.26$} & \multicolumn{3}{|c|}{ Model 2: $R^{2}=.38$} & \multicolumn{3}{|c|}{ Model 2: $R^{2}=.45$} \\
\hline & Beta & $T$ & $p$ & Beta & $T$ & $p$ & Beta & $T$ & $p$ \\
\hline Constant & & 15.561 & $<.0001$ & & 11.289 & $<.0001$ & & 9.405 & $<.0001$ \\
\hline \multicolumn{10}{|l|}{$\begin{array}{l}\text { Spirituality indica- } \\
\text { tors }\end{array}$} \\
\hline Faith as strong hold & -.176 & -3.483 & .001 & -.111 & -2.287 & .023 & -.111 & -2.387 & .018 \\
\hline Longing for God & -.192 & -3.598 & $<.0001$ & -.120 & -2.359 & .019 & -.094 & -1.952 & .052 \\
\hline $\begin{array}{l}\text { Frequency of } \\
\text { praying }\end{array}$ & -.148 & -2.794 & .006 & .237 & 4.931 & $<.0001$ & .135 & 2.764 & .006 \\
\hline $\begin{array}{l}\text { Frequency of } \\
\text { meditation }\end{array}$ & .313 & 6.310 & $<.0001$ & -.114 & -2.323 & .021 & -.133 & -2.825 & .005 \\
\hline \multicolumn{10}{|l|}{$\begin{array}{l}\text { Quality of Life } \\
\text { Indicators }\end{array}$} \\
\hline Life satisfaction & & & & -.168 & -3.225 & .001 & -.107 & -2.112 & .036 \\
\hline Wellbeing & & & & -.086 & -1.659 & .098 & -.060 & -1.227 & .221 \\
\hline $\begin{array}{l}\text { Restricted in daily } \\
\text { life activities }\end{array}$ & & & & -.226 & -4.317 & $<.0001$ & -.192 & -3.787 & $<.0001$ \\
\hline $\begin{array}{l}\text { Loneliness/social } \\
\text { isolation }\end{array}$ & & & & .173 & 3.208 & .001 & .146 & 2.830 & .005 \\
\hline $\begin{array}{l}\text { Burdening finan- } \\
\text { cial situation }\end{array}$ & & & & .086 & 1.620 & .106 & .081 & 1.605 & .109 \\
\hline \multicolumn{10}{|l|}{ Health behaviors } \\
\hline $\begin{array}{l}\text { Mood-enhancing } \\
\text { medications }\end{array}$ & & & & & & & .223 & 4.353 & $<.0001$ \\
\hline
\end{tabular}

Data without "other" participants

analyzed variables would predict $38 \%$ of variance. Adding the intake of moodenhancing medications in regression model 3, the best predictors are the usage of mood-enhancing medications (as a positive predictor) and being restricted in daily life concerns (still as a negative predictor). These variables would altogether explain $45 \%$ of SDS score variance.

\section{Praying and Meditation and Their Association with Spiritual Dryness, Restrictions, Life Satisfaction and Health Behaviors}

It is important to underline that the frequencies of praying and meditation are not associated $(r=0.00)$. Those who meditate more often have lower perceptions of being restricted in their daily life activities $(r=-0.26)$, but have marginally lower life satisfaction $(r=-0.17)$, while they use mood-enhancing medications more often $(r=0.43)$. In contrast, those who pray more often have higher life satisfaction $(r=0.24)$, while there is no relevant association with perceptions of being restricted in daily life $(r=0.07)$; however, praying is not relevantly associated with the usage 
Table 7 Frequency of praying and meditation related to spiritual dryness, stressors, life satisfaction and wellbeing

$\begin{array}{lllll}\text { Spiritual } & \text { Restricted in } & \text { Loneliness/ } & \text { Life satisfac- } & \text { Wellbeing } \\ \text { dryness } & \text { daily life activi- } & \text { social isola- } & \text { tion (BMLSS- } & \text { (WHO-5) } \\ \text { (SDS) } & \text { ties } & \text { tion } & 10) & \end{array}$

All persons $(n=331)$

$\begin{array}{llllll}\text { Mean } & 1.63 & 39.06 & 37.94 & 55.82 & 55.04 \\ \text { SD } & 0.81 & 27.23 & 28.79 & 16.23 & 15.68\end{array}$

Praying

Never $(n=22)$

Mean

SD

1.76

43.64

0.72

24.79

At least once per month $(n=75)$

Mean

SD

1.82

36.27

27.35

39.19

27.09

50.90

53.68

0.63

1.87

35.19

0.74

25.83

40.19

53.54

55.13

SD

At least once per day $(n=127)$

Mean
SD
$F$ value
$p$ value
Meditation
Never $(n=96)$
Mean
SD

At least once per month $(n=69)$

Mean

SD

$\begin{array}{ll}1.29 & 42.60 \\ 0.86 & 28.46 \\ 13.35 & 1.90 \\ <.0001 & \text { n.s }\end{array}$

1.18

51.56

0.80

28.70

40.00

60.17

53.25

29.20

17.33

17.43

$1.68 \quad 38.41$

26.21

34.64

53.42

54.32

0.68

26.88

15.34

16.81

At least once per week $(n=99)$

Mean

SD

$1.85 \quad 30.81$

24.15

38.16

55.61

56.75

0.68

30.06

15.08

13.75

At least once per day ( $n=67)$

\begin{tabular}{clllll} 
Mean & 1.89 & 34.03 & 38.06 & 52.36 & 55.82 \\
SD & 0.85 & 24.31 & 28.51 & 16.09 & 14.50 \\
$F$ value & 16.95 & 11.57 & 0.47 & 3.92 & 0.91 \\
$p$ value & $<.0001$ & $<.0001$ & n.s & .009 & n.s \\
\hline
\end{tabular}


of mood-enhancing medications $(r=-0.01)$. Neither of the spiritual practices is related to wellbeing $(r=0.052$ and 0.053$)$.

In the light of these findings, one can state that those who were praying at least once per day had the lowest spiritual dryness scores compared to those who prayed at least once per week. Additionally, they had the highest life satisfaction, while there were no significant differences for stressors (being restricted in daily life activities or loneliness/social isolation) and wellbeing (Table 7). In contrast, those who were never meditating had the lowest spiritual dryness scores, while those who meditated at least once per week or at a daily level had the highest spiritual dryness scores (indicating that meditation could have been used to cope). Furthermore, those who were never meditating had the highest perception of being restricted in daily life and the highest life satisfaction.

\section{Discussion}

Although the results of a comparative study (Asadzandi et al., 2020), conducted to compare the spiritual health behaviors of Iranians during the COVID-19 pandemic, showed that religious beliefs had a positive effect on the spiritual health of people, the findings of the current study underlined that the phases of spiritual dryness are nevertheless experienced by several participants. $27 \%$ of them perceived these phases often regularly. One may suggest the influence of the COVID-19 pandemicrelated stressors on the participants' SDS scores. However, among these cases, only a few were related to spiritual dryness. While the weak association between spiritual dryness and loneliness/social isolation is plausible from the conceptual point of view, which was found in another study, too (Büssing, et al., 2017a, 2017b), the perceptions of daily life restrictions due to the pandemic were, however, inversely related to spiritual dryness. This contra-intuitive association is so far difficult to explain, as a buffering effect seems unlikely.

Perceiving spiritual dryness is not necessarily a matter of "weakness in faith" or personal "failure," but a complex spiritual and psychosocial development process (Büssing et al., 2020a). Some people, particularly when facing negative life events, feel that God has forgotten them, or that the event is a punishment from God, and they doubt God's power and think that He is unkind (Exline et al., 2015). In such a situation, it seems that there is either a lack of deep inner relationship with God or a less stable one (in terms of confidence and trust) (Büssing et al., 2020b, 2021c), and the fear of punishment and rejection by God is felt by the individual. Sometimes illnesses or difficult circumstances cause spiritual and religious crises in individuals that may reduce adaptation mechanisms and increase their anxiety levels (Mirhosseini 2020). In a qualitative study conducted in Iran, disappointment, the futility of praying and the feeling of being rejected by God were the emerging themes (Nemati et al., 2017). The participants revealed that they felt deprived of the divine attention and that they had lost their faith in spirituality. Some of them believed that God was not noticing them or their prayers were not being answered. Unanswered prayers had led the participants to a feeling of being rejected by God. These perceptions are identical to the symptoms of spiritual dryness (Büssing et al., 2013), as reported in 
this study, too. The participants who reached this point appeared to have a defensive reaction to their spiritual beliefs that, in the most extreme cases, emerged as the ignoring of other people's religious beliefs and insistence on their own position (Nemati et al., 2017).

All relationships can, in terms of the attachment theory, experience such difficulties in terms of trust, confidence, hope, distance and misunderstandings. This is applicable for the relationship with God, too (Kelley \& Chan, 2012; Parenteau et al., 2019). Even when it is theologically and cognitively true that God is always with us (even when a faithful person may have distanced himself from God), the emotional perception that God is distant and not responding may nevertheless be an individual process of pain and grief (Büssing \& Dienberg, 2019). In these situations, people require dedicated support-not in the sense of instruction, but understanding and accompaniment. As $24 \%$ of the participants stated that they often to regularly have the perception that God has abandoned them completely, and 32\% sometimes had this perception, there is a clear demand to care for the people who might be at the crossroads of faith. Nevertheless, $42 \%$ stated that they have often to regularly found strategies and resources to cope with these perceptions, while $28 \%$ either had not found these strategies at all or had seldom found them. This again underlines that spiritual and/or psychological support is required for the people who do not have access to their resources. According to Musapur et al. (2020), identifying the spiritual and existential transformation of these individuals as a kind of perceptual process to cope with the crisis can help healthcare providers to support them better.

As it has been found in this study, there are some indicators showing who in particular experiences the phases of spiritual dryness. This group includes, namely men and the people who cannot rely on their faith as a resource, those who less often pray, those with low life satisfaction and those who feel lonely and socially isolated because of the pandemic. In many cases, religious people may feel that the current life situation is due to the will of God, as well as other difficult situations. On the other hand, people may also experience that God is not responding as they had expected and feel not "worthy enough" or even abandoned (Büssing et al., 2020b). As a consequence, some may not find inner peace, experience religious struggles, stop praying, etc. (Shirinabadi Farahani et al., 2020).

The positive association between spiritual dryness and taking mood-enhancing medications and meditation practice in this study could be seen in terms of a strategy to cope either with these perceptions and/or with the pandemic-related restrictions. In Iran, many people can buy antidepressants or antianxiety medications from pharmacies without a doctor's prescription, even though it is not legal (Margdari Nejad et al., 2017). The results of a study conducted in Iran demonstrated that perceived stress, physical complaints, anxiety and depression predict sedative use (Gilan et al., 2015). The inability to express emotions may hinder emotional regulation and prohibit successful adjustment, leading to these individuals' having reduced adjustment capabilities in stressful situations. Perceived stress predicts sedative drug use, possibly because stress and tension produce restlessness and the individual therefore takes drugs to reduce the tension (Gilan et al., 2015). With respect to the frequency of praying (which is negatively related to spiritual dryness because the perceptions that prayers go unanswered are part of the distance perception) it is important to 
differentiate the frequency of prayers. Interestingly, those who pray at a daily level had the lowest SDS scores and the highest life satisfaction. This indicates that their religious trust and their relation with God seem to be stable which also influences their general life satisfaction. On the other hand, the participants who pray only once a week or once a month had the highest spiritual dryness scores, indicating that their relation with God might be less stable, particularly those who pray at least once per month had the lowest life satisfaction and wellbeing. In Iran, religious practices such as prayers are also among the most important approaches to promoting individual health (Shirinabadi Farahani et al., 2020). However, the frequency of praying is not related to the feeling of being restricted in life, lonely or socially isolated due to the pandemic.

With respect to the predictors of spiritual dryness, regression analyses revealed a complex pattern of triggers, enhancers and putative buffers. The best predictor was taking mood-enhancing medication, probably as an easily accessible strategy to cope with the negative perceptions of spiritual struggles and spiritual exhaustion, which is part of the process. Loneliness (because of the pandemic) and low life satisfaction are relevant predictors that could imply dissatisfaction with the current life and may also affect spiritual wellbeing and relation with God. With the entry of quality of life indicators in the regression model, there was a switch of predictor loading in terms of praying and meditation. Praying was first a negative predictor and meditation a positive one, while praying finally became a positive predictor and meditation a negative one. This might be explained in part by the aforementioned differential usage of praying and meditation intensity. In a study which aimed to investigate the effect of transcendental meditation (as spiritual care) on the spiritual wellbeing of type- 2 diabetic amputees, the results confirmed the usefulness of the meditation technique in improving spiritual well-being in the intervention group (Movahed et al., 2020). Moreover, meditation not only may reduce stress (Kemper et al, 2011), but also has positive effects on the quality of life (Dreger et al., 2015), the improvement of spiritual wellbeing (Hartmann et al, 2012) and the increase of hope (Fallah et al., 2011). Accordingly, we have to consider different religious groups (also with respect to their Faith as a strong hold in difficult times) which differ in life satisfaction, too.

However, there is also a positive spiritual development process that should be considered. When the phases of spiritual dryness were overcome, most stated that these feelings inspired them "to help others more" on the one hand and a perception of "greater spiritual serenity and depth" on the other hand. This can indicate a process of spiritual transformation (Büssing et al., 2018b) with both a prosocial and a spiritual direction. According to Tedeschi and Calhoun (1996), although stressful events can result in adverse physical, mental and social effects, the struggle with such events may lead to posttraumatic growth in different aspects of life. Five multidimensional constructs comprise the posttraumatic growth model: personal strength, relating to others, appreciation of life, spiritual changes and new possibilities. However, during the COVID-19 pandemic, these growth processes could be perceived by those who have reliable resources available, but not by all (Büssing et al., 2020c, 2021a, 2021c). As overcoming the phases of spiritual dryness has inspired several individuals to care more for others and to experience a greater spiritual serenity and depth, indicating posttraumatic growth and spiritual transformation despite or 
because of the pandemic. It is important to provide support in case of crises such as COVID-19 pandemic for all individuals.

\section{Limitations}

The survey was started during the COVID-19 pandemic, which affected the lives of people worldwide, resulting in a decrease of wellbeing and increase of fears and worries. The possibility that this situation has negatively influenced the participants' perceptions in terms of spiritual dryness cannot be ignored. So far, we have no pre-pandemic data for comparison.

This study was primarily an online survey, and the people without internet access were not able to participate in it. Therefore, it cannot be assumed that our findings are the representative of all Iranian Muslims. Nevertheless, the age range indicates that the elderlies have also participated in the study.

As this study has a cross-sectional design, the direction of causation is of course unclear. For example, the participants may either have experienced the phases of spiritual dryness independently because of the pandemic of or may have perceived the pandemic-related restrictions more strongly because of underlying struggles with God, etc. This can be clarified only in longitudinal studies or qualitative interviews.

\section{Conclusions}

Spirituality and faith are usually reported to be the resources to cope with difficult life situations and may provide meaning in life, hope, inspiration and finding a hold, particularly when one is able to rely on positive religious coping strategies (ThunéBoyle et al., 2006). However, there are also phases of spiritual dryness, which may challenge religious peoples' faith and trust in a caring God. This study has found that spiritual dryness is also experienced among Iranian Muslims who participated in this study during the Covid-19 pandemic. The researchers have identified a complex pattern of predictors that may buffer or trigger these perceptions. These perceptions should not be regarded as indicators of "weakness in faith" but as a phase in the lives of devoted religious people. Particularly, the COVID-19 is a challenge that affects the mental stability of people worldwide and is not a matter of surprise that this situation may challenge trust in God, too. Therefore, reliable and humble support of people experiencing these phases is required, as it might be that they are more sensitive toward spiritual struggles than others. Perhaps those who have experienced and overcome these phases have a better understanding that God's ways are different than man's expectations and are therefore more compassionate toward those who struggle with their faith and with God. At least, this was found in a large fraction of people in this study. Those who respond to these experiences seem to show solidary with those who live far from God. This could be an important task particularly in times of social crisis. 
Authors Contributions AB designed the study and set up the online survey. SHK and MR translated the instruments and initiated the sampling processes. $\mathrm{AB}$ undertook statistical analyses. $\mathrm{AB}, \mathrm{MR}$ and SHK wrote the first draft of the paper, and all authors provided feedback. All authors approved the final manuscript.

Funding Open Access funding enabled and organized by Projekt DEAL. There was no external funding supporting this study.

Availability of Data and Material According to the data protection regulations, the data set cannot be made publicly available. The data can, however, be available upon a reasonable request to the authors.

\section{Declarations}

Conflict of interest The authors declare that the research was conducted in the absence of any commercial or financial relationships that could be considered as a potential conflict of interest.

Open Access This article is licensed under a Creative Commons Attribution 4.0 International License, which permits use, sharing, adaptation, distribution and reproduction in any medium or format, as long as you give appropriate credit to the original author(s) and the source, provide a link to the Creative Commons licence, and indicate if changes were made. The images or other third party material in this article are included in the article's Creative Commons licence, unless indicated otherwise in a credit line to the material. If material is not included in the article's Creative Commons licence and your intended use is not permitted by statutory regulation or exceeds the permitted use, you will need to obtain permission directly from the copyright holder. To view a copy of this licence, visit http://creativecommons.org/licen ses/by/4.0/.

\section{References}

Alzahrani, S. H., Bashawri, J., Salawati, E. M., \& Bakarman, M. A. (2016). Knowledge and attitudes towards complementary and alternative medicine among senior medical students in King Abdulaziz University, Saudi Arabia. Evidence-Based Complementary and Alternative Medicine, 3(1), 6-15. https://doi.org/10.1155/2016/9370721

Asadzandi, M., Abolghasemi, H., Javadi, M., \& Sarhangi, F. (2020). A Comparative assessment of the spiritual health behaviors of the Iranian Muslim in the COVID-19 pandemic with religious evidence. Journal of Military Medicine, 22(8), 864-872. https://doi.org/10.1007/s10943-019-00950-3

Barmania, S., \& Reiss, M. J. (2020). Health promotion perspectives on the COVID-19 pandemic: The importance of religion. Global Health Promotion, 28, 15-22. https://doi.org/10.1177/1757975920 972992

Bäumer, R., \& Plattig, M. (2008). "Dunkle Nacht” und Depression: Geistliche und psychologische Krisen verstehen und unterscheiden ["Dark Night" and Depression: Understanding and Differentiating between Spiritual and Psychological Crises]. Matthias-Grünewald-Verlag.

Bech, P., Olsen, L. R., Kjoller, M., \& Rasmussen, N. K. (2003). Measuring well-being rather than the absence of distress symptoms: A comparison of the SF-36 Mental Health subscale and the WHOFive well-being scale. International Journal of Methods in Psychiatric Research, 12(2), 85-91. https://doi.org/10.1002/mpr.145

Büntzel, J., Klein, M., Keinki, C., Walter, S., Büntzel, J., \& Hübner, J. (2020). Oncology services in corona times: A flash interview among German cancer patients and their physicians. Journal of Cancer Research and Clinical Oncology, 146(10), 2713-2715. https://doi.org/10.1007/ s00432-020-03249-z

Büssing, A., \& Fischer, J. (2009). Interpretation of illness in cancer survivors is associated with healthrelated variables and adaptive coping styles. BMC Women's Health, 9, 2. https://doi.org/10.1186/ 1472-6874-9-2 
Büssing, A., Fischer, J., Haller, A., Heusser, P., Ostermann, T., \& Matthiessen, P. F. (2009). Validation of the brief multidimensional life satisfaction scale in patients with chronic diseases. European Journal of Medical Research, 14(4), 171-177. https://doi.org/10.1186/2047-783x-14-4-171

Büssing, A. (2012). Measures. In M. Cobb, C. Puchalski, \& B. Rumbold (Eds.), Oxford textbook of spirituality in healthcare (pp. 323-331). Oxford University Press.

Büssing, A., Günther, A., Baumann, K., Frick, E., \& Jacobs, C. (2013). Spiritual dryness as a measure of a specific spiritual crisis in catholic priests: Associations with symptoms of burnout and distress. Evidence-Based Complementary and Alternative Medicine, 2013, 246797. https://doi.org/10.1155/ 2013/246797

Büssing, A., Recchia, D. R., \& Baumann, K. (2015). Reliance on God's Help Scale as a measure of religious trust-A summary of findings. Religions, 6(4), 1358-1367. https://doi.org/10.3390/rel60 41358

Büssing, A., \& Surzykiewicz, J. (2015). Interpretation of illness in patients with chronic diseases from Poland and their associations with spirituality, life satisfaction, and escape from illness-Results from a cross sectional study. Religions, 6(3), 763-780. https://doi.org/10.3390/rel6030763

Büssing, A., Frick, E., Jacobs, C., \& Baumann, K. (2016). Spiritual dryness in non-ordained Catholic pastoral workers. Religions, 7(12), 141. https://doi.org/10.3390/rel7120141

Büssing, A., Baumann, K., Jacobs, C., \& Frick, E. (2017a). Spiritual dryness in Catholic priests: Internal resources as possible buffers. Psychology of Religion and Spirituality, 9(1), 46-55. https://doi.org/ $10.1037 /$ rel0000063

Büssing, A., Frick, E., Jacobs, C., \& Baumann, K. (2017b). Self-attributed importance of spiritual practices in Catholic pastoral workers and their association with life satisfaction. Pastoral Psychology, 66(3), 295-310. https://doi.org/10.1007/s11089-016-0746-9

Büssing, A., Baiocco, F., \& Baumann, K. (2018a). Spiritual dryness in catholic laypersons working as volunteers is related to reduced life satisfaction rather than to indicators of spirituality. Pastoral Psychology, 67(1), 1-15. https://doi.org/10.1007/s11089-017-0798-5

Büssing, A., Recchia, D. R., \& Dienberg, T. (2018b). Attitudes and behaviors related to Franciscaninspired spirituality and their associations with compassion and altruism in Franciscan brothers and sisters. Religions, 9, 324. https://doi.org/10.3390/rel9100324

Büssing, A., Recchia, D. R., \& Baumann, K. (2018c). Validation of the gratitude/awe questionnaire and its association with disposition of gratefulness. Religions, 9, 117. https://doi.org/10.3390/re190 40117

Büssing, A. (2019). Geistliche Trockenheit bei Seelsorgern und Ordens-Christen [Spiritual dryness among pastoral workers and religious Christians]. In A. Büssing \& T. Dienberg (Eds.), Geistliche Trockenheit-empirisch, theologisch, in der Begleitung [Spiritual dryness - empirical, theological, accompanied] (pp. 79-103). Aschendorf Verlag.

Büssing, A., \& Dienberg, T. (2019). Geistliche Trockenheit bei Seelsorgern und Ordens-Christen. Geistliche Trockenheit-empirisch, theologisch, in der Begleitung [Spiritual dryness - empirical, theological, accompanied]. Münster: Aschendorf Verlag.

Büssing, A., Beerenbrock, Y., Gerundt, M., \& Berger, B. (2020a). Triggers of spiritual dryness. Results from qualitative interviews with religious brothers and sisters. Pastoral Psychology, 69, 99-117. https://doi.org/10.1007/s11089-020-00898-2

Büssing, A., Winter, S., \& Baumann, K. (2020b). Perception of religious brothers and sisters and lay persons that prayers go unanswered is a matter of perceived distance from God. Religions, 11, 178. https://doi.org/10.3390/rel11040178

Büssing, A., Recchia, D. R., Hein, R., \& Dienberg, T. (2020c). Perceived changes of specific attitudes, perceptions and behaviors during the Corona pandemic and their relation to wellbeing. Health and Quality of Life Outcomes, 18(1), 374. https://doi.org/10.1186/s12955-020-01623-6

Büssing, A., Hübner, J., Walter, S., Gießler, W., \& Büntzel, J. (2020d). Tumor patients' perceived changes of specific attitudes, perceptions and behaviors due to the Corona pandemic and its relation to reduced wellbeing. Frontiers in Psychiatry, 11, 574314. https://doi.org/10.3389/fpsyt.2020.574314

Büssing, A., Recchia, D. R., Hübner, J., Walter, S., Büntzel, J., \& Büntzel, J. (2021a). Tumor patients' fears and worries and perceived changes of specific attitudes, perceptions and behaviors due to the COVID-19 pandemic are still relevant. Journal of Cancer Research and Clinical Oncology, 147, 1673-1683. https://doi.org/10.1007/s00432-021-03573-y

Büssing, A., Starck, L., \& van Treeck, K. (2021c). Experience of spiritual dryness and acedia symptoms in Seventh-day Adventists. Journal of Religion and Health, 60(2), 1261-1280. https://doi.org/10. 1007/s10943-020-01092-7 
Caldeira, S., Timmins, F., de Carvalho, E. C., \& Vieira, M. (2017). Spiritual well-being and spiritual distress in cancer patients undergoing chemotherapy: Utilizing the SWBQ as component of holistic nursing diagnosis. Journal of Religion and Health, 56(4), 1489-1502. https://doi.org/10.1007/ s10943-017-0390-4

Currier, J. M., McDermott, R. C., McCormick, W. H., Churchwell, M. C., \& Milkeris, L. (2018). Exploring cross-lagged associations between spiritual struggles and risk for suicidal behavior in a community sample of military veterans. Journal of Affective Disorders, 230, 93-100. https://doi.org/10. 1016/j.jad.2018.01.009

Currier, J. M., Foster, J. D., \& Isaak, S. L. (2019). Moral injury and spiritual struggles in military veterans: A latent profile analysis. Journal of Traumatic Stress, 32(3), 393-404. https://doi.org/10.1002/ jts. 22378

Daaleman, T. P., \& VandeCreek, L. (2000). Placing religion and spirituality in end-of-life care. JAMA, 284(19), 2514-2517. https://doi.org/10.1001/jama.284.19.2514

Degner, L. F., Hack, T., O'Neil, J., \& Kristjanson, L. J. (2003). A new approach to eliciting meaning in the context of breast cancer. Cancer Nursing, 26(3), 169-178. https://doi.org/10.1097/00002820200306000-00001

Dreger, L. C., Mackenzie, C., \& McLeod, B. (2015). Feasibility of a mindfulness-based intervention for aboriginal adults with type 2 diabetes. Mindfulness, 6(2), 264-280. https://doi.org/10.1007/ s12671-013-0257-z

Durà-Vilà, G. (2017). Sadness, depression, and the dark night of the soul: Transcending the medicalisation of sadness. Jessica Kingsley Publishers.

Exline, J. J., Grubbs, J. B., \& Homolka, S. J. (2015). Seeing god as cruel or distant: links with divine struggles involving anger, doubt, and fear of God's disapproval. The International Journal for the Psychology of Religion, 25(1), 29-41. https://doi.org/10.1080/10508619.2013.857255

Exline, J. J., Pargament, K. I., Grubbs, J. B., \& Yali, A. M. (2014). The religious and spiritual struggles scale: Development and initial validation. Psychology of Religion and Spirituality, 6(3), 208-222. https://doi.org/10.1037/a0036465

Exline, J. J., \& Rose, E. D. (2013). Religious and spiritual struggles. In R. F. Paloutzian \& C. L. Park (Eds.), Handbook of the psychology of religion and spirituality (2nd ed., pp. 380-398). Guilford Press.

Fallah, R., Golzari, M., Dastani, M., \& Akbari, M. (2011). Integrating spirituality into a group psychotherapy program for women surviving from breast cancer. Iranian Journal of Cancer Prevention, 4(3), 141-147.

Gilan, N. R., Zakiei, A., Reshadat, S., Komasi, S., \& Ghasemi, S. R. (2015). Perceived stress, alexithymia, and psychological health as predictors of sedative abuse. Korean Journal of Family Medicine, 36(5), 210-215. https://doi.org/10.4082/kjfm.2015.36.5.210

Hartmann, M., Kopf, S., Kircher, C., Faude-Lang, V., Djuric, Z., Augstein, F., Friederich, H.-C., Kieser, M., Bierhaus, A., Humpert, P. M., Herzog, W., \& Nawroth, P. P. (2012). Sustained effects of a mindfulness-based stress-reduction intervention in type 2 diabetic patients: Design and first results of a randomized controlled trial (the Heidelberger Diabetes and Stress-study. Diabetes Care, 35(5), 945-947. https://doi.org/10.2337/dc11-1343

Heidari, M., Heidari, A., \& Yoosefee, S. (2020). COVID-19 pandemic and the necessity of spiritual care. Iranian Journal of Psychiatry, 15(3), 262-263. https://doi.org/10.18502/ijps.v15i3.3823

Janů, A., Malinakova, K., Kosarkova, A., \& Tavel, P. (2020). Associations of childhood trauma experiences with religious and spiritual struggles. Journal of Health Psychology, 23, 1359105320950793. https://doi.org/10.1177/1359105320950793

Kelley, M. M., \& Chan, K. T. (2012). Assessing the role of attachment to God, meaning, and religious coping as mediators in the grief experience. Death Studies, 36(3), 199-227. https://doi.org/10.1080/ 07481187.2011 .553317

Kemper, K., Bulla, S., Krueger, D., Ott, M. J., McCool, J. A., \& Gardiner, P. (2011). Nurses' experiences, expectations, and preferences for mind-body practices to reduce stress. BMC Complementary and Alternative Medicine, 11, 26. https://doi.org/10.1186/1472-6882-11-26

Kowalczyk, O., Roszkowski, K., Montane, X., Pawliszak, W., Tylkowski, B., \& Bajek, A. (2020). Religion and faith perception in a pandemic of COVID-19. Journal of Religion and Health, 59(6), 2671-2677. https://doi.org/10.1007/s10943-020-01088-3

Lips-Wiersma, M. (2002). The influence of spiritual "meaning-making" on career behavior. Journal of Management Development, 21(7), 497-520. https://doi.org/10.1108/02621710210434638 
Margdari Nejad, M., Kazemi, S., Khosravi, M., Sanagoo, A., \& Jouybari, L. (2017). The prevalence of non-prescription drugs and related factors in students of medical sciences in 1392. Iran Journal of Nursing, 29(104), 66-74. https://doi.org/10.29252/ijn.29.104.66

Martini, C. M., \& Bader, W. (2005). Auch die Seele kennt Tag und Nacht: Reflexionen für Zeiten innerer Prüfung [Also the soul knows day and night: Reflections for times of inner testing]. Verlag Neue Stadt.

May, G. G. (2009). The dark night of the soul: A psychiatrist explores the connection between darkness and spiritual growth. HarperOne.

Memaryan, N., Rassouli, M., \& Mehrabi, M. (2016). Spirituality Concept by Health Professionals in Iran: A Qualitative Study. Evidence-Based Complementary and Alternative Medicine, 2016, 8913870. https://doi.org/10.1155/2016/8913870

Motahhari, M. (2013). Adl-e-Elahi [Divine Justice]. Sadra Publication.

Movahed, A. H., Sabouhi, F., Mohammadpourhodki, R., Mahdavi, S., Goudarzian, S., Amerian, M., Mohtashami, M., \& Imeni, M. K. (2020). Investigating the effect of transcendental meditation on spiritual wellbeing of Type-2 diabetic amputees: A clinical trial study. Heliyon, 6(11), e05567. https://doi.org/10.1016/j.heliyon.2020.e05567

Musapur, H. C. A. J., \& KahrobaeiKalkhuranAlya, M. (2020). Spiritual and existential growth and COVID 19 pandemic: A qualitative study. Journal of Research in Psychological Health, 14(1), 56-70.

Nemati, S., Rassouli, M., \& Baghestani, A. R. (2017). The spiritual challenges faced by family caregivers of patients with cancer: A qualitative study. Holistic Nursing Practice, 31(2), 110-117. https://doi.org/10.1097/HNP.0000000000000198

Nolan, T. S., Browning, K., Vo, J. B., Meadows, R. J., \& Paxton, R. J. (2020). CE: Assessing and managing spiritual distress in cancer survivorship. The American Journal of Nursing, 120(1), 40-47. https://doi.org/10.1097/01.NAJ.0000652032.51780.56

Ott, E. (1982). Die dunkle Nacht der Seele: Depression? - Untersuchung zur geistlichen Dimension der Schwermut [The dark night of the soul: Depression? - Investigation into the spiritual dimension of melancholy]. Novalis Verlag.

Parenteau, S. C., Hurd, K., Wu, H., \& Feck, C. (2019). Attachment to god and psychological adjustment: God's responses and our coping strategies. Journal of Religion and Health, 58(4), 12861306. https://doi.org/10.1007/s10943-019-00765-2

Puchalski, C. M., King, S. D., \& Ferrell, B. R. (2018). Spiritual considerations. Hematology/oncology Clinics of North America, 32(3), 505-517. https://doi.org/10.1016/j.hoc.2018.01.011

Rahnama, M., Khoshknab, M. F., Maddah, S. S. B., \& Ahmadi, F. (2012). Iranian cancer patients' perception of spirituality: A qualitative content analysis study. BMC Nursing, 11(1), 19. https:// doi.org/10.1186/1472-6955-11-19

Rassouli, M., Ashrafizadeh, H., Shirinabadi Farahani, A., \& Akbari, M. E. (2020). COVID-19 management in Iran as one of the most affected countries in the world: Advantages and weaknesses. Frontiers in Public Health, 8, 510. https://doi.org/10.3389/fpubh.2020.00510

Rassouli, M., \& Sajjadi, M. (2016). Palliative care in Iran: Moving toward the development of palliative care for cancer. American Journal of Hospice and Palliative Medicine, 33(3), 240-244. https://doi.org/10.1177/1049909114561856

Rezaee, N., Mardani-Hamooleh, M., \& Seraji, M. (2020). Nurses' perception of ethical challenges in caring for patients with COVID-19: a qualitative analysis. Journal of Medical Ethics and History of Medicine, 13(1), 23-30. https://doi.org/10.18502/jmehm.v13i23.4954

Rokni, M. (2008). Tehran divine justice (Vol. 1). Iran: Islamic Revolutionary Guard Corps, Representation of the Supreme Leader, Office of Political Ideological Education. http://lib.eshia.ir/ $26355 / 1 / 7$.

Roman, N. V., Mthembu, T. G., \& Hoosen, M. (2020). Spiritual care-'A deeper immunity'-A response to Covid-19 pandemic. African Journal of Primary Health Care \& Family Medicine, 12(1), 35-43. https://doi.org/10.4102/phcfm.v12i1.2456

Shirinabadi Farahani, A., Büssing, A., Akbari, M., Ashrafizadeh, H., Heidarzadeh, M., Hatamipour, K., Tabatabaie, A., Ansari, M., Karami, M., Fallahi, S., Khademi, F., Pakseresht, M., \& Rassouli, M. (2020). The translation and psychometric evaluation of the Persian version of brief multidimensional life satisfaction scale for Iranian cancer patients. International Journal of Cancer Management, 14(7), e113588. https://doi.org/10.5812/ijcm.113588 
Smucker, C. (1996). A phenomenological description of the experience of spiritual distress. International Journal of Nursing Terminologies and Classifications, 7(2), 81-91. https://doi.org/10.1111/j.1744618x.1996.tb00297.x

Soleimani, M., Bastani, F., \& Negarandeh, R. (2016). Exploring of challenges of self-care in people with Parkinson's disease: Resulting from qualitative research study. Journal of Gerontology, 1(1), 63-78. https://doi.org/10.18869/acadpub.joge.1.1.1

Stauner, N., Exline, J. J., \& Pargament, K. I. (2016). Religious and spiritual struggles as concerns for health and well-being. Horizonte, 14(41), 48-75. https://doi.org/10.5752/P.2175-5841.2016v14n41 $\mathrm{p} 48$

Stauner, N., Exline, J. J., Kusina, J. R., \& Pargament, K. I. (2019). Religious and spiritual struggles, religiousness, and alcohol problems among undergraduates. Journal of Prevention \& Intervention in the Community, 47(3), 243-258. https://doi.org/10.1080/10852352.2019.1603678

Tedeschi, R. G., \& Calhoun, L. G. (1996). The Posttraumatic Growth Inventory: Measuring the positive legacy of trauma. Journal of Traumatic Stress, 9(3), 455-471. https://doi.org/10.1007/BF02103658

Thuné-Boyle, I. C., Stygall, J. A., Keshtgar, M. R., \& Newman, S. P. (2006). Do religious/spiritual coping strategies affect illness adjustment in patients with cancer? A systematic review of the literature. Social Science \& Medicine, 63(1), 151-164. https://doi.org/10.1016/j.socscimed.2005.11.055

Topp, C. W., Østergaard, S. D., Søndergaard, S., \& Bech, P. (2015). The WHO-5 Well-Being Index: A systematic review of the literature. Psychotherapy and Psychosomatics, 84(3), 167-176. https://doi. org/10.1159/000376585

Weber, S. R., \& Pargament, K. I. (2014). The role of religion and spirituality in mental health. Current Opinion in Psychiatry, 27(5), 358-363. https://doi.org/10.1097/YCO.0000000000000080

Publisher's Note Springer Nature remains neutral with regard to jurisdictional claims in published maps and institutional affiliations. 